\title{
The clinical characteristics and molecular mechanism of pituitary adenoma associated with meningioma
}

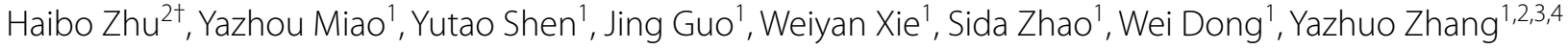 \\ and Chuzhong $\mathrm{Li}^{1,2,3,4^{*}}$
}

\begin{abstract}
Background: Pituitary adenoma and meningioma are the most common benign tumors in the central nervous system. Pituitary adenoma associated with meningioma (PAM) is a rare disease and the clinical features and mechanisms of PAM are unclear.

Methods: We summarized the clinical data of 57 PAM patients and compared with sporadic pituitary adenoma (SPA) and sporadic meningioma (SM). 5 pituitary adenomas of PAM and 5 SPAs were performed ceRNA microarray. qRT-PCR, Western Blot, siMEN1 and rapamycin inhibition experiment were validated for ceRNA microarray.

Results: Clinical variable analyses revealed that significant correlations between PAM and female sex as well as older age when compared with SPA and significant correlations between PAM and transitional meningioma as well as older age when compared with SM. Additionally, the characteristics of PAM were significantly different for MEN1 patients. Functional experiments showed lower expression of MEN1 can upregulate mTOR signaling, in accordance with the result of ceRNA microarray. Rapamycin treatment promotes apoptosis in primary pituitary adenoma and meningioma cells of PAM.
\end{abstract}

Conclusions: MEN1 plays an important role in PAM by upregulating mTOR signaling pathway. Rapamycin represents a potential therapeutic strategy for PAM in the future.

Keywords: Clinical characteristics, Molecular mechanism, MEN1, PAM, mTOR

\section{Background}

Pituitary adenoma and meningioma are the most common benign tumors in the central nervous system (CNS); pituitary adenomas represent a heterogeneous group of extra-axial neoplasms that collectively comprise approximately $13 \%$ of all intracranial tumors with an incidence of approximately 3 per 100,000 [1,2]. Meningiomas are generally slow-growing tumors derived from the arachnoid membrane surrounding the central nervous system and they are among the most common intracranial tumors, with an overall incidence of 6 per 100,000 (15-25\% of

\footnotetext{
*Correspondence: lichuzhong@sina.com

${ }^{+}$Haibo Zhu-First author

${ }^{1}$ Beijing Neurosurgical Institute, Capital Medical University, No. 119, South

Fourth Ring West Road, Fengtai District, Beijing 100070, China

Full list of author information is available at the end of the article
}

all brain tumors) and a 2:1 female to male ratio [3-6]. PAM is a rare clinical situation, and there were only 33 cases described before 2017 [7]. The precise cause for the development of PAM remains unknown. There are three possible explanations for PAM, including chance occurrence, environmental influence, or genetic predisposition. Currently there are no known epidemiological or well-characterized genetic associations between meningioma and pituitary adenoma.

Multiple endocrine neoplasia type 1 (MEN1) is an autosomal dominant disease caused by germline MEN1 mutations that leads to the development of multi-focal neoplastic endocrine lesions of the parathyroid glands, endocrine pancreas, duodenum, anterior pituitary, and, less commonly, stomach, adrenal cortex, thymus, and lungs [8-10]. In addition, various non-endocrine lesions

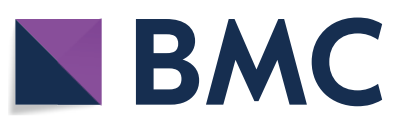

(c) The Author(s) 2019. This article is distributed under the terms of the Creative Commons Attribution 4.0 International License (http://creativecommons.org/licenses/by/4.0/), which permits unrestricted use, distribution, and reproduction in any medium, provided you give appropriate credit to the original author(s) and the source, provide a link to the Creative Commons license, and indicate if changes were made. The Creative Commons Public Domain Dedication waiver (http://creativecommons.org/ publicdomain/zero/1.0/) applies to the data made available in this article, unless otherwise stated. 
may occur in the skin, CNS, and soft tissues. Asgharian et al. [11] reported that meningioma may be a component tumor of MEN1, and it is believed that alterations in the MEN1 gene may participates in its pathogenesis.

Hyperactivation of the $\mathrm{PI} 3 \mathrm{~K} / \mathrm{AKT} / \mathrm{mTOR}$ signaling pathway is found in many types of human cancers, and play key roles in regulating cell growth and tumorigenesis $[12,13]$. Pachow et al. [14] reported that mTOR activation plays an important role in brain tumor pathogenesis and growth, including sporadic and syndromic brain tumors. Mutations in negative regulators of the mTOR pathway, such as PTEN, TSC1/TSC2 and NF1 are important for the tumorigenesis of familial cancer predisposition syndromes. $\mathrm{Li}$ et al. [15] reported that the mTOR pathway was related to the tumorigenesis of gonadotrophin adenoma. Meningioma samples have also been shown to express high levels of mTORC1 and S6K, implicating mTORC1 as a relevant signaling pathway in meningiomas [16]. In the present study, we found that lower expression of MEN1 play an important role in PAM by upregulating the mTOR signaling pathway. Rapamycin represents a potential therapeutic strategy for PAM in the future.

\section{Materials and methods}

\section{Patients}

We retrospectively reviewed pituitary adenoma patients in Beijing Tiantan Hospital from January 1, 2005 to December 31, 2017. All patients were classified according to preoperative images, including hormone, plain and enhanced head MRI, thin layer skull base CT scanning and three-dimensional reconstruction. Patients who suffered from meningioma and pituitary adenoma simultaneously or successively were included in this study. The present study was conducted in accordance with established ethical guidelines as outlined in the Declaration of Helsinki. We obtained written informed consent from all participants, and the Ethics Committee of Beijing Tian$\tan$ Hospital approved this study.

\section{ceRNA microarrays and construction of pathway act network}

ceRNA means competing endogenous RNA. ceRNA microarray includes mRNA, lncRNA and circRNA. 5 pituitary adenomas of PAM and 5 SPAs were performed ceRNA microarray (Additional file 1: Table S1). Total RNA was extracted and purified using a mirVana ${ }^{\mathrm{TM}}$ miRNA Isolation Kit without phenol (Cat \# AM1561, Ambion, Austin, TX, US). RNA samples from each group were then used to generate fluorescence-labeled cRNA targets for the SBC human ceRNA array V1.0 $(4 \times 180 \mathrm{~K})$. The labeled cRNA targets were then hybridized with the slides. After hybridization, the slides were scanned on an
Agilent Microarray Scanner (Agilent Technologies, Santa Clara, CA, US). The data were extracted with Feature Extraction software 10.7 (Agilent Technologies, Santa Clara, CA, US). Raw data were normalized by the Quantile algorithm using the limma package of the R program. The microarray experiments were performed according to the protocol of Agilent Technologies, Inc. at Shanghai Biotechnology Corporation. Ratios were calculated between the PAM and SPA. Then, differentially expressed genes were identified by using the t-test with a cut-off criteria of $\mathrm{P}<0.05$ and fold-change $>2$ or $<0.5$.

The selected mRNAs were grouped in functional categories based on the Gene Ontology database (GO: http:// www.geneontology.org/). We identified the significant pathways of the differentially expressed genes by using IPA software (http://www.ingenuity.com). We used the software Cytoscape software (V2.8.0) (http://www.cytos cape.org) to construct a pathway act network for graphical representations of central pathways using the genes enriched in the significant canonical pathways of IPA $(\mathrm{P}<0.05)$.

\section{Quantitative real-time PCR validation}

Total RNA was extracted using TRIzol reagent (Invitrogen, USA) and then reversed transcribed using a HiFiScript gDNA Removal cDNA Synthesis Kit (CWBio, China) according to the manufacturer's instructions. Subsequently, we performed qRT-PCR using SYBR Green assays in a total reaction volume of $10 \mu \mathrm{l}$ which was performed on an ABI 7500 System (Applied Biosystems). GAPDH was used as a reference gene. For the quantitative analysis, expression levels were calculated based on $\mathrm{CT}$ values (corrected for GAPDH expression) according to the equation: $2^{-\Delta C T}[\Delta C T=C T$ (gene of interest)-CT (GAPDH)]. All qRT-PCR analyses were performed in triplicate. Student's t-tests were applied, and a P-value $<0.05$ was considered significant. The primer sequences are presented in Additional file 2: Table S2.

\section{Short interfering RNA transfection of HEK 293T cells}

$293 \mathrm{~T}$ cells were authenticated by China Infrastructure of Cell Line Resource and tested negative for mycoplasma according to China Infrastructure of Cell Line Resource. Short interfering RNA (siRNA) against MEN1 (si-MEN1) and the negative control (sh-NC) were synthesized by RiboBio (Guangzhou, China) and employed (SiMEN1 CTACGACGGCATCTGCAAA). Exponentially growing HEK $293 \mathrm{~T}$ cells $\left(2 \times 10^{5}\right)$ were seeded onto 6-well plates overnight, and then transfected using Lipofectamine ${ }^{\circledR} 3000$ transfection reagent (Thermo Fisher Scientific, Massachusetts, USA) (final concentration: siRNA or negative control: $50 \mathrm{nM})$. The transfection 
efficiency was determined by qRT-PCR at $48 \mathrm{~h}$ after transfection. The protein extracted from transfected cells was collected to measure the level of MEN1and mTOR pathway genes by Western blot at $72 \mathrm{~h}$ after transfection.

\section{Western blot}

Transfected 293T cells were lysed in nondenaturing lysis buffer (Applygen). For Western blotting, the protein samples $(30 \mu \mathrm{g})$ were separated by $10 \%$ sodium dodecyl sulfate polyacrylamide gel electrophoresis and then transferred to polyvinylidene difluoride membranes. Different blots were incubated with antibodies against MEN1 (ab 92443, 1:5000, Abcam, USA), phosphor-AKT(1:1000, AF0016, Affinity, China), AKT(1:500, 10176-2-AP, Proteintech, USA), phospho-mTOR(1:500, AF3308, Affinity, China), mTOR(1:300, 20657-1-AP, Proteintech, USA) or vinculin(1:10,000, Abcam, USA), followed by incubation with secondary antibodies tagged with horseradish peroxidase (Santa Cruz Biotechnology). The blots were visualized by enhanced chemiluminescence, and densitometry was performed with an imaging apparatus (Amersham Imager 600, GE). Vinculin was used as a loading control.

\section{Isolation and culture of primary pituitary adenoma and meningioma cells of PAM}

Before isolating primary pituitary adenoma and meningioma cells, all pituitary adenoma and meningioma biopsies were washed in PBS supplemented with $\mathrm{P} / \mathrm{S}$ and $10 \%$ FBS in order to remove unhealthy tissues. After carefully washing, the remaining healthy tissues were cut into small pieces using refined scissors and dissociated into small cell clumps (10-50 cells/clump) with prechilled accutase. Then these small clumps of primary pituitary adenoma and meningioma cells were collected and re-suspended in cell culture medium: DMEM/F12 (Invitrogen), 1\% Knock Out serum replacement (KSR, Invitrogen), N2 supplement (100X, Invitrogen), B27 supplement (100X, Invitrogen), $1 \mathrm{mM}$ L-Glutamine, $0.1 \mathrm{mM}$ NEAA, $0.1 \mathrm{mM} 2-\mathrm{ME}$ with $4 \mathrm{ng} / \mathrm{ml}$ bFGF (R\&D systems), and $10 \mathrm{ng} / \mathrm{ml}$ EGF (R\&D systems). After evaluating the cell number and viability, primary pituitary adenoma and meningioma cells were seeded at $2 \times 10^{5}$ cells/well (6 well plate) on Matrigel-embedded plate. The medium was replenished every $24 \mathrm{~h}$ for $5-7$ days before passaging. Pituitary adenoma and meningioma cells can be passaged by accutase digestion and can be routinely maintained in cell culture medium for $5-10$ passages.

\section{Apoptosis induction assays}

For the human FAS;CD95 ELISA assay, pituitary adenoma cells were plated into 96 well plate at $2 \times 10^{4}$ cells/ well and treated with rapamycin at $0 \mathrm{nM}, 0.5 \mathrm{nM}, 1 \mathrm{nM}$,
$2 \mathrm{nM}$. and Meningioma cells were plated into 96 well plate at $2 \times 10^{4}$ cells/well and treated with rapamycin at $0 \mathrm{nM}, 1 \mathrm{nM}, 2 \mathrm{nM}, 5 \mathrm{nM}, 10 \mathrm{nM}$. Supernatants were collected at $48 \mathrm{~h}$ and $72 \mathrm{~h}$ for apoptosis detection. Apoptosis index was measured following the instruction of the human FAS;CD95 ELISA kit (KS4622, Keshun biotechnology).

For the annexin V Conjugates based assay, pituitary adenoma cells were plated into 96 well plate at $2 \times 10^{6}$ cells/well and treated with rapamycin at $0.5 \mathrm{nM}$, $1 \mathrm{nM}, 2 \mathrm{nM}$. Meningioma cells were plated into 96 well plate at $2 \times 10^{6}$ cells/well and treated with rapamycin at $2 \mathrm{nM}, 5 \mathrm{nM}, 10 \mathrm{nM}$. Supernatants were collected at $48 \mathrm{~h}$ and $72 \mathrm{~h}$ for apoptosis detection. Cells were then treated with Annexin V Alexa Fluor 488 to identify apoptotic cells by flow cytometry.

\section{Statistical analysis}

Statistical analysis was performed using SPSS software (version 20.0, IBM). The $\chi^{2}$ test was used to analyze metric variables. The two independent-samples $t$ test was used to test ordinal variables. P-values of $<0.05$ were defined as a significant difference.

\section{Results}

\section{Clinical features}

A total of 8197 pituitary adenoma patients from January 1, 2005 to December 31, 2017, were retrospectively analyzed; of these, $57(0.7 \%)$ patients met the criteria for PAM (Additional file 3: Table S3). The average age was $54.2 \pm 9.8$ years (ranging from 20 to 71 years), with 44 female and 13 male patients. In 55 PAM patients, 51 were diagnosed as pituitary adenoma and meningioma simultaneously, 4 were diagnosed with meningioma first, and 2 were diagnosed with pituitary adenoma first. All pituitary adenomas were resected, with 20 invasive, 34 noninvasive, and 3 not applicable, including $1 \mathrm{ACTH}, 6 \mathrm{GH}$, $1 \mathrm{GH}+$ PRL, 34 NFPA and 7 PRL cases. Meningiomas were located at different positions, including 17 brain convex, 12 parafalcine, 7 skull base, 6 tentorium cerebelli, 5 cerebellopontine angle, 4 multiple, 3 parasagittal, 2 orbital and 1 T9-10 cases (Fig. 1). 18 meningiomas were resected, and there were 11 transitional, 5 fibrous and 2 endothelial meningioma. A total of 134 SPAs and 399 SMs were involved in the present study for clinical variable statistical analysis (Additional file 4: Table S4). Clinical variable analyses between PAM and SM revealed significant correlations between PAM and transitional meningioma $(P=0.018)$ and older age $(P=0.05)$. Clinical variable analyses between PAM and SPA revealed that significant correlations of PAM with female sex $(\mathrm{P}=0.0007)$ and older age $(\mathrm{P}<0.0001)($ Fig. 2$)$. 

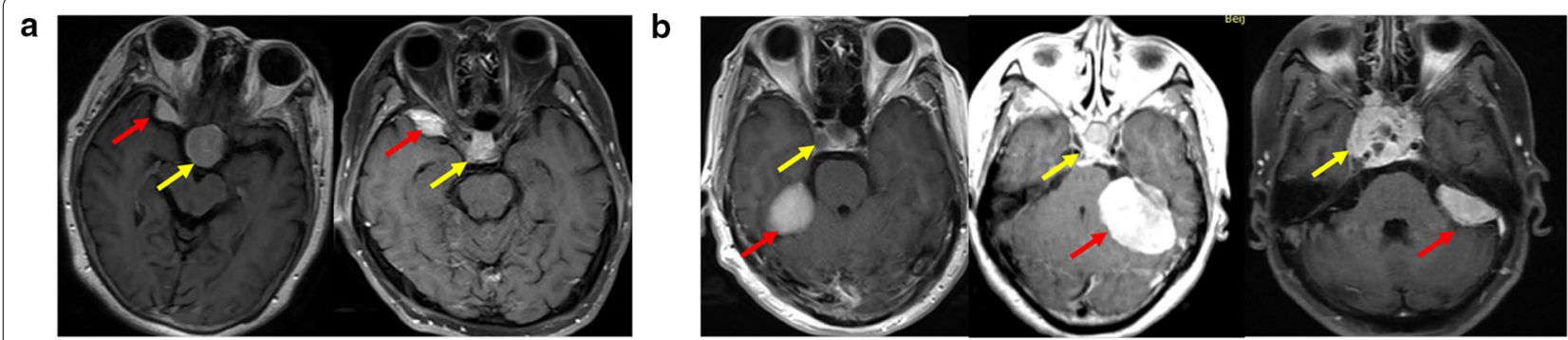

c
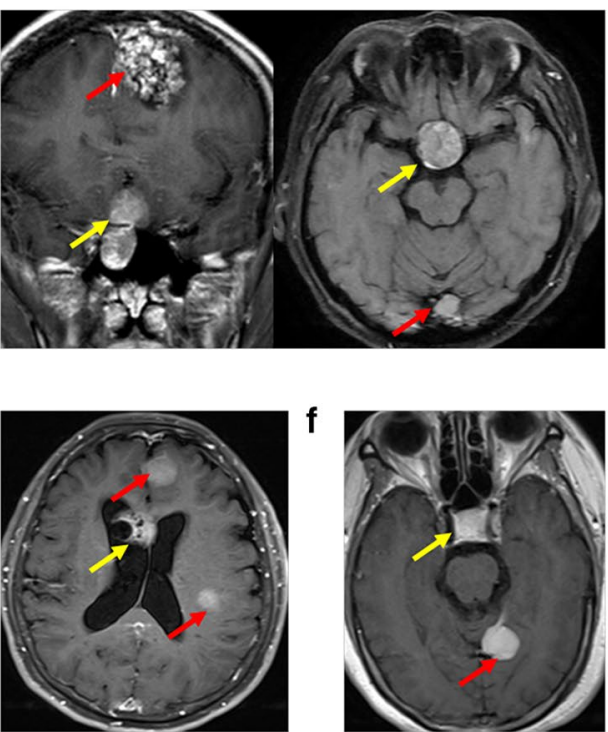

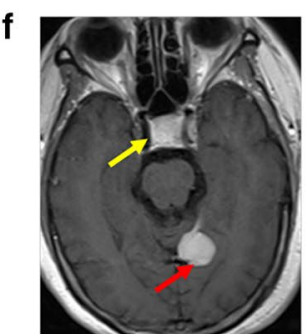

d

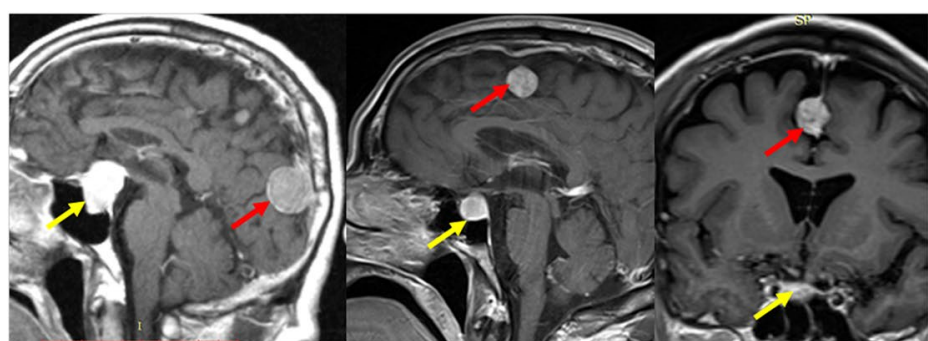

g
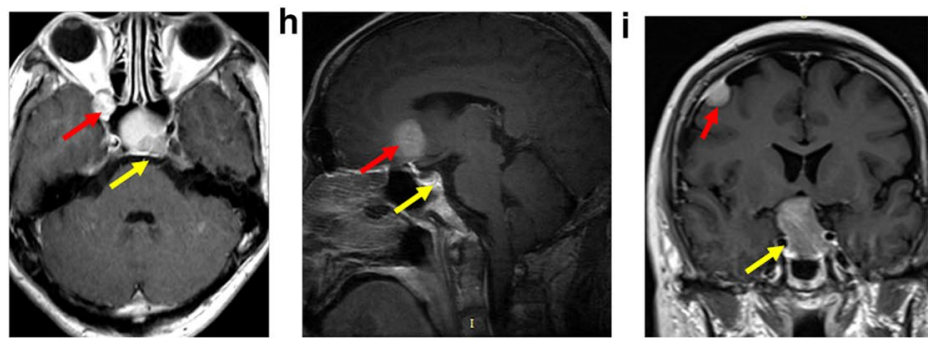

Fig. 1 Pituitary adenoma associated with meningioma which located different anatomical region: a sphenoid ridge; b cerebellopontine angle; c parasagittal; $\mathbf{d}$ parafalcine; e multiple; $\mathbf{f}$ tentorium cerebelli; $\mathbf{g}$ orbital; $\mathbf{h}$ tuberculum sellae; $\mathbf{i}$ brain convex. Red arrow indicate meningioma and yellow arrow indicate pituitary adenoma
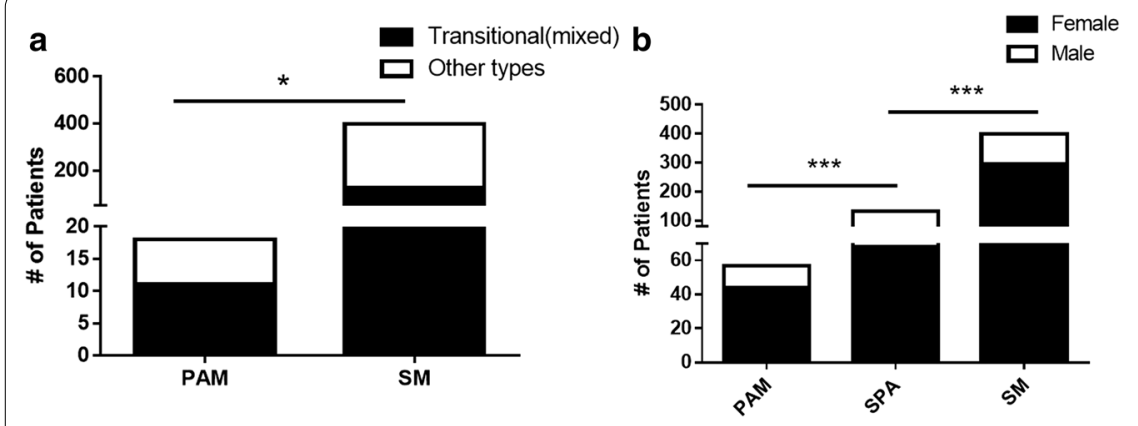

C

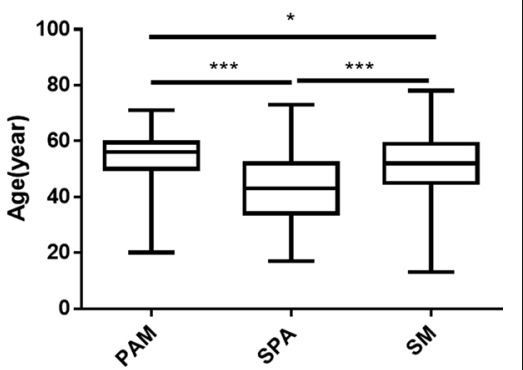

Fig. 2 Clinical variable analyses between PAM and SPA, SM: a pathological difference between PAM and SM; $\mathbf{b}$ sex difference between PAM and SPA, SM; $\mathbf{c}$ age difference between PAM and SPA, SM. ${ }^{*} P<0.05,{ }^{* * P}<0.01,{ }^{* * *} P<0.001$

Identified differentially expressed mRNAs by transcriptome microarrays

Compared with SPAs, 10188 mRNAs were significantly differentially expressed in pituitary adenomas of PAM, including 8918 upregulated and 1270 downregulated
mRNAs (Additional file 5: Table S5). Correlation plot analysis showed that the correlation between the samples of the two groups was low and the correlation between the samples of each group was high (Fig. 3a). Hierarchical clustering showed that the expression patterns of the 


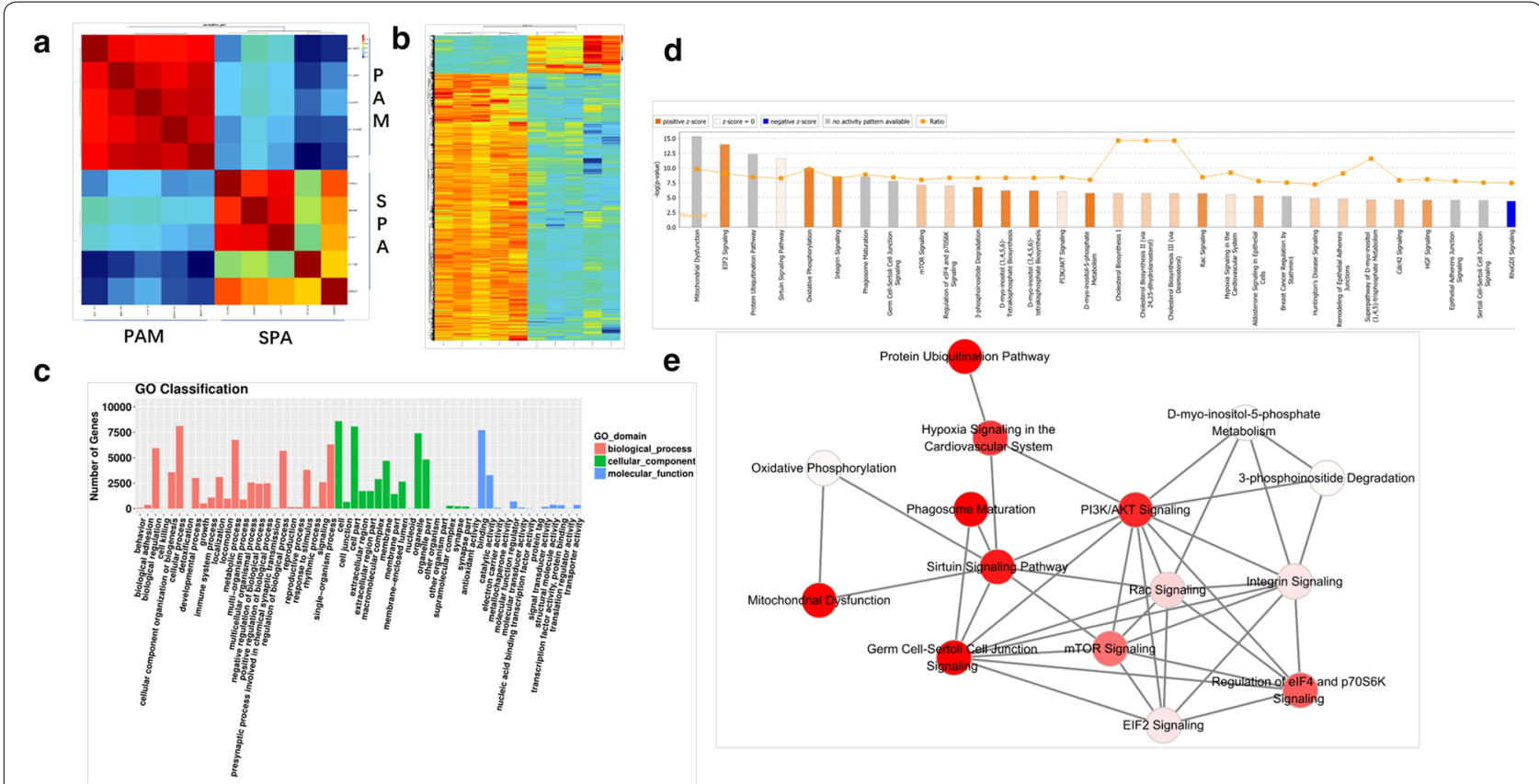

Fig. 3 Correlation analysis and Cytoscape pathway act network by transcription microarray: a correlation plot showed the correlation between each sample. The brightness of the color represents the degree of correlation between the samples. Red indicates high correlation and blue indicates low correlation; $\mathbf{b}$ heat map shows the expression profiles of mRNAs between pituitary adenoma samples of PAM and SPA samples (FC $>2$ or $<0.5$ and $P<0.05$ ), each row represents a single $m R N A$, and each column represents one sample. Red indicates high expression and green indicates low expression; c go annotation of differentially expressed mRNAs with the enrichment covering domains of biological processes, cellular components and molecular functions; $\mathbf{d}$ IPA pathway analysis of mRNAs enriched in the top thirty pathways according to the P-value; $\mathbf{e}$ Cytoscape pathway act network: Pathway act network according to the overlap of common differentially expressed molecules in top 15 significant canonical pathways. The node color is associated with pathway status. Red indicates that the signaling pathway is activated contrast to green indicates that the signaling pathway is suppressed. Grey indicates that the pathway is unpredicted

mRNAs between the two groups were distinguishable (Fig. 3b).

\section{GO and IPA analysis of differentially expressed mRNAs}

GO analysis was performed to study the biological processes, cellular components and specific molecular functions of all differentially expressed mRNAs. We performed GO analysis of the mRNAs that were differentially expressed between the two groups. The results showed that the biological processes mainly involved the cellular process, metabolic process, regulation of biological process and single-organism process; the cellular components mainly involved the cell, cell part, and organelle; and the molecular functions mainly involved binding and catalytic activity (Fig. 3c). IPA pathway analysis targeting differentially expressed mRNAs (the top 30 pathways with the highest enrichment scores were selected) revealed that differentially expressed mRNAs were mainly involved in Mitochondrial Dysfunction, EIF2 Signaling, Protein Ubiquitination Pathway, Sirtuin Signaling Pathway, Oxidative Phosphorylation, Integrin
Signaling, Phagosome Maturation, Germ Cell-Sertoli Cell Junction Signaling, mTOR Signaling, etc. (Fig. 3d).

\section{Cytoscape pathway act network}

We used Cystoscope to construct a pathway act network according to the overlap of common differentially expressed molecules in the top 15 canonical pathways (Fig. 3e). The results showed that the protein ubiquitination pathway, mTOR signaling, PI3K/AKT signaling, Regulation of eIF4 and p70S6K signaling, Mitochondrial dysfunction, Sirtuin Signaling, Phagosome maturation, Germ cell-sertoli cell junction signaling pathway and Hypoxia signaling in the cardiovascular system were activated in the network. The mTOR signaling pathway was the core node in the pathway network. We selected the mTOR pathway for further verification.

\section{Validation of microarray data by qRT-PCR and Western Blot} Based on the bioinformatics prediction, we selected 7 mRNAs of the mTOR signaling pathway, and the results showed that the expression levels of MEN1, AKT, mTOR, 4E-BP1, p70S6K and PTEN were significantly different between the two groups (Fig. 4a). Compared with SPAs 


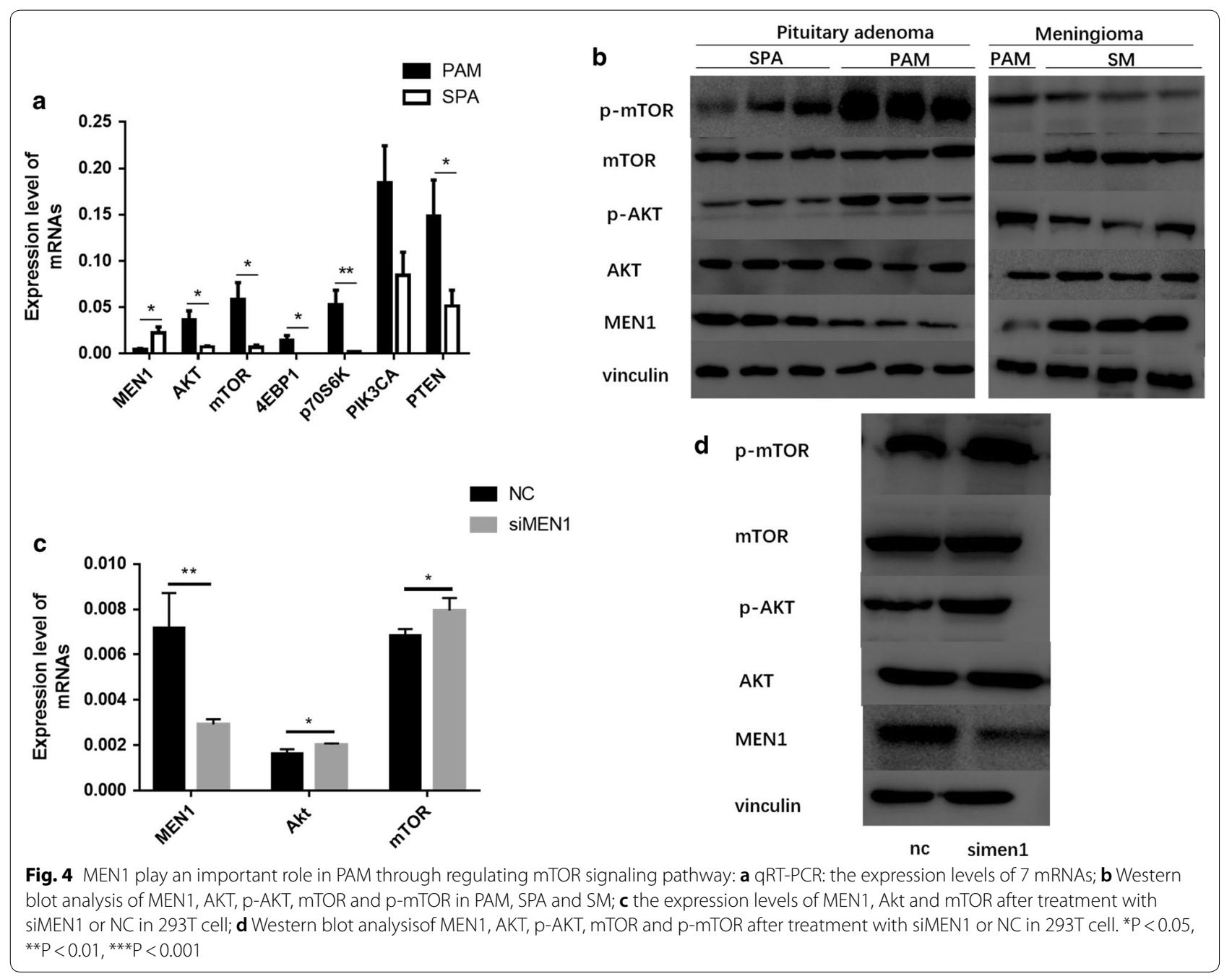

and SMs, the protein p-AKT (phosphorylated at Ser473), p-mTOR (phosphorylated at Ser2448) all showed increasing expression trend, and MEN1 showed reducing expression trend in pituitary adenoma and meningioma samples of PAM (Fig. 4b).

\section{siMEN1 promoted the expression of mTOR signaling pathway genes}

The factors involved in the AKT/mTOR pathway have been known to participate in the tumorigenesis and tumor progression of pituitary adenoma and meningioma $[15,17,18]$. The interfering efficiency for siMEN1 was observed at $48 \mathrm{~h}$ after transfection. The gene expression levels of AKT and mTOR were significantly increased and the expression level of MEN1 was significantly reduced (Fig. 4c). When their total and phosphorylated protein levels were detected, the proteins $\mathrm{p}-\mathrm{AKT}$ (phosphorylated at Ser473) and p-mTOR (phosphorylated at Ser2448) showed an increasing expression trend, and MEN1 showed a reducing expression trend (Fig. 4d). These results suggested that the low expression of MEN1 could activate the expression of factors involved in the mTOR signaling pathway.

\section{Rapamycin promotes apoptosis in primary pituitary adenoma and meningioma cells of PAM}

Elisa analysis demonstrated that rapamycin upregulated FAS expression in a dose-dependent manner in primary pituitary adenoma and meningioma cells of PAM (Fig. 5a, f). FITC-Annexin V/PI double staining was used to detect apoptosis in primary pituitary adenoma and meningioma cells of PAM following rapamycin treatment. Following treatment with $2 \mathrm{nM}$ rapamycin in primary pituitary adenoma cells, the rate of apoptosis $(P=0.013)$ and the level of FAS $(P=0.029)$ significantly increased compared with the control (Fig. 5b-e). Following treatment with $10 \mathrm{nM}$ rapamycin in primary meningioma cells, the rate of apoptosis $(\mathrm{P}=0.003)$ and the level 

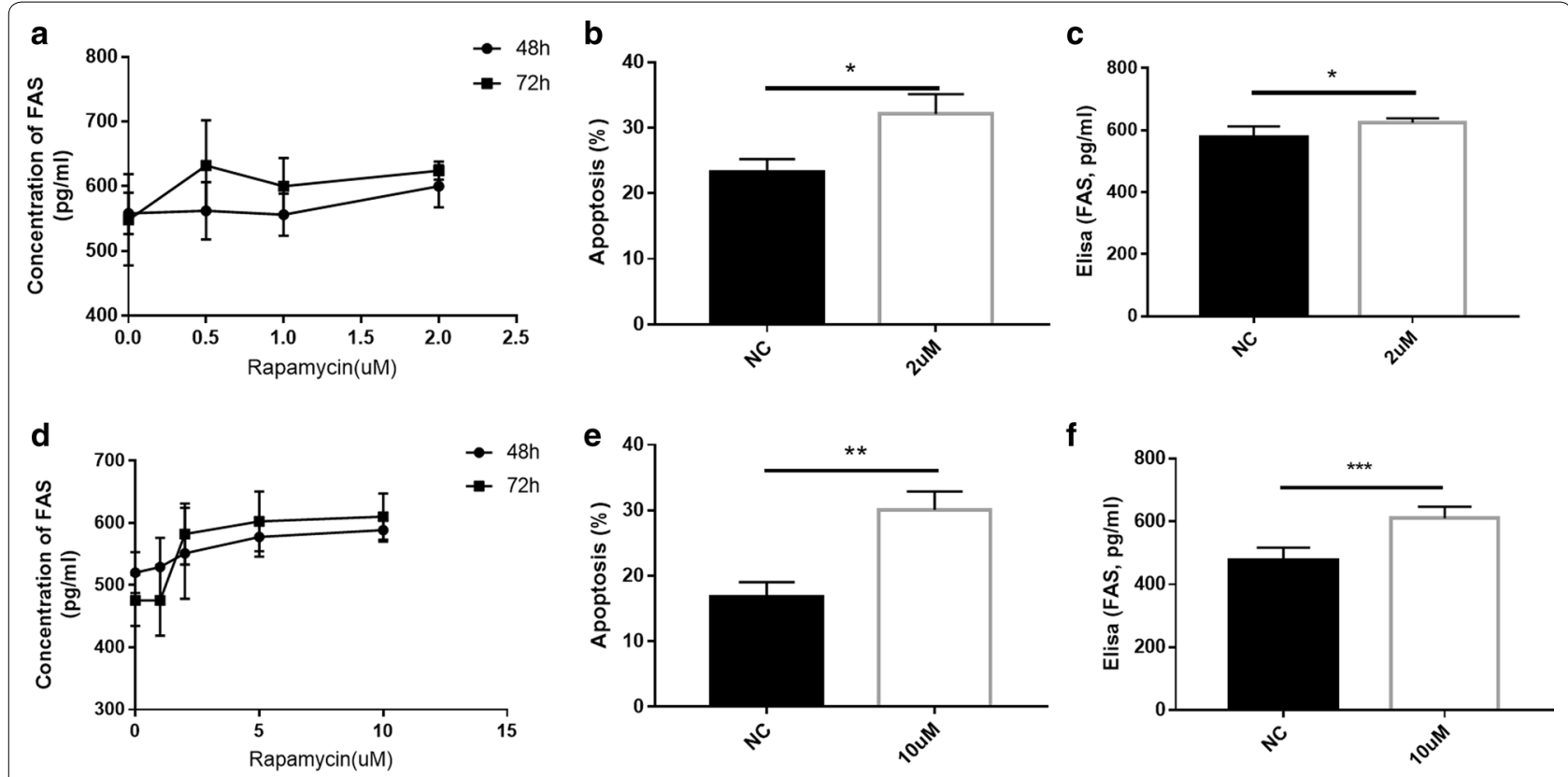

Fig. 5 Rapamycin promotes apoptosis in primary pituitary adenoma and meningioma cells of PAM: a Flow cytometry revealing that the apoptosis rate of primary pituitary adenoma cells of PAM increased following treatment with rapamycin treatment in a dose-dependent manner for $48 \mathrm{~h}$ and $72 \mathrm{~h}$; b Flow cytometry revealing that the apoptosis rate of primary pituitary adenoma cells increased following treatment with rapamycin $2 \mathrm{nM}$ for $72 \mathrm{~h}$; c Flow cytometry revealing that the FAS concentration of primary pituitary adenoma cells increased following treatment with rapamycin $2 \mathrm{nM}$ for $72 \mathrm{~h}$; d Flow cytometry revealing that the apoptosis rate of primary meningioma cells of PAM increased following treatment with rapamycin treatment in a dose-dependent manner for $48 \mathrm{~h}$ and $72 \mathrm{~h}$; e Flow cytometry revealing that the apoptosis rate of primary meningioma cells increased following treatment with rapamycin $10 \mathrm{nM}$ for $72 \mathrm{~h}$; f Flow cytometry revealing that the FAS concentration of primary pituitary adenoma cells increased following treatment with rapamycin $10 \mathrm{nM}$ for $72 \mathrm{~h}^{*} \mathrm{P}<0.05,{ }^{* *} \mathrm{P}<0.01$, ${ }^{* * *} \mathrm{P}<0.001$

of FAS $(P=0.0006)$ significantly increased compared with the control (Fig. $5 \mathrm{~g}-\mathrm{j}$ ). These results indicated that rapamycin treatment promotes apoptosis in primary pituitary adenoma and meningioma cells of PAM. In the future, rapamycin represent potential therapeutic strategy for PAM.

\section{Discussion}

Pituitary adenoma and meningioma are the most common benign tumors in the CNS; there were only 33 PAMs described before 2017 [7]. We summarized 8197 pituitary adenomas in our hospital, and there were 57 PAMs, 5 pituitary adenoma associated with glioma and 5 pituitary adenoma associated with schwannoglioma in the present study. The incidence of meningioma between the normal population $(6 / 100,000)$ and pituitary adenoma patients (7/1000) had a significant difference. A recent study reported that meningioma of PAM may be associated with GH and IGF-1 levels and radiology [19]. However, in the present study, there were only $6 \mathrm{GH}$ patients and the 2 PAM patients who were diagnosed with pituitary adenoma first had no history of radiotherapy. There may be a common genetic mechanism leading to PAM.
The PI3K/AKT/mTOR signaling pathway plays a key role in regulating cell proliferation, cell growth, apoptosis and metabolism [20,21]. Some studies reported that the PI3K/AKT/mTOR pathway plays an important role in pituitary adenoma and meningioma [15-18]. A recent study reported that both sporadic and syndromic brain tumors are related to hyperactivation of mTOR [14]. Li et al. reported that $M E N 1 /$ Menin regulates milk protein synthesis through mTOR signaling in mammary epithelia cells. Mafficini et al. [22] reviewed that MEN1 can regulate mTOR pathway by inhibiting AKT in pancreatic neuroendocrine tumors. In the present study, we found that compared with SPA or SM, the expression of MEN1 was lower and the mTOR signaling pathway was hyperactivated in PAM patients. Therefore, lower expression of MEN1 plays an important role in PAM by regulating mTOR signaling pathway.

Inhibition of the mTOR signaling pathway has become an attractive target for human cancer therapy. Rapamycin is an mTOR inhibitor with potent immunosuppressive and antiproliferative effects [23]. Several clinical trials using mTOR inhibitors to treat brain tumors showed that the clinical value of single or combined treatment of primary or recurrent glioblastoma is unclear [24-26]. 
However, subependymal giant cell astrocytomas (SEGAs) are characterized by high expression levels of activated (phosphorylated) S6K, and these tumors are exquisitely responsive to treatment with the mTORC1 inhibitor everolimus [27-29]. Additionally, no pituitary adenoma and meningioma clinical studies have been reported so far, but a recent study showed that mTORC1 inhibitors suppress meningioma growth in mouse models; thus, meningiomas might represent a suitable target [16]. Cerovac et al. [30] reported that adjuvant treatment with a somatostatin analogue can sensitize pituitary tumor cells to the anti-proliferative effects of rapamycin. In the present study, we found that rapamycin treatment promotes apoptosis in primary cells of pituitary adenoma and meningioma of PAM. Therefore, these results indicated that rapamycin represent potential therapeutic strategy for PAM in the future.

\section{Conclusion}

Taken together, There are significant correlations between PAM and female sex as well as older age when compared with SPA and significant correlations between PAM and transitional meningioma as well as older age when compared with SM.MEN1 plays an important role in PAM by upregulating mTOR signaling pathway. Rapamycin represents a potential therapeutic strategy for PAM in the future.

\section{Supplementary information}

Supplementary information accompanies this paper at https://doi. org/10.1186/s12967-019-2103-0.

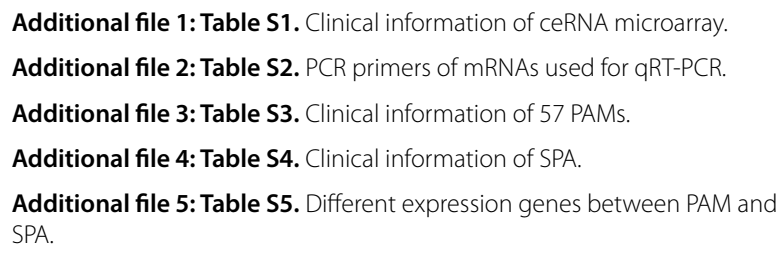

\section{Abbreviations}

PAM: pituitary adenoma associated with meningioma; SPA: sporadic pituitary adenoma; SM: sporadic meningioma; siRNA: small interfering RNA; GO: gene ontology; IPA: Ingenuity Pathway Analysis; ceRNA: competing endogenous RNA; MEN1: multiple endocrine neoplasia 1; CNS: central nervous system; FFPE: Formalin-Fixed and Paraffin-Embedded; CCF: cancer cell fraction.

\section{Acknowledgements}

We thank Dr. Chengcheng Wang (Etiology Laboratory, National Cancer Center/Cancer Hospital Chinese Academy of Medical Sciences) for support with experiments. We thank Dr. Zhexuan Li (Epidemiological Laboratory, Beijing Cancer Hospital/Beijing Institute For Cancer Research) for support of statistics. We thank Mr. Lei Gong and Mrs. Hongyun Wang (Cell Laboratory, Beijing Neurosurgical Institute) for support with technique.

\section{Authors' contributions}

HBZ, CHL and YZZ were responsible for the research design. HBZ, YZM, JG and YTS participated in the sample collection and clinical data collection.
HBZ, SDZ and WYX participated in performing the experiment. HBZ and CZL contributed to the manuscript writing and submission. HBZ, YZM, JG and WD were responsible for the statistical analyses and figure formatting. CZL and YZZ participated in the funding application and management of the project. All authors have contributed the final manuscript. All authors read and approved the final manuscript.

\section{Funding}

This work was supported by grants from the National High Technology Research and Development Program of China (863 Program, 2014AA020610), National Natural Science Foundation of China (81771489), Beijing Municipal Science \& Technology Commission (Z171100000117002) and China National Key Research and Development Program (2017YFC0908300).

\section{Availability of data and materials}

The datasets during and/or analyzed during the current study available from the corresponding author on reasonable request.

\section{Ethics approval and consent to participate}

This study was approved by the medical ethics committee of Beijing Tiantan Hospital.

\section{Consent for publication}

All the authors in this paper consent to publication of the work.

\section{Competing interests}

The authors declare that they have no competing interests.

\section{Author details}

${ }^{1}$ Beijing Neurosurgical Institute, Capital Medical University, No. 119, South Fourth Ring West Road, Fengtai District, Beijing 100070, China. ${ }^{2}$ Department of Neurosurgery, Beijing Tiantan Hospital affiliated to Capital Medical University, No. 119, South Fourth Ring West Road, Fengtai District, Beijing 100070, China. ${ }^{3}$ Beijing Institute for Brain Disorders Brain Tumor Center, No. 119, South Fourth Ring West Road, Fengtai District, Beijing 100070, China. ${ }^{4}$ China National Clinical Research Center for Neurological Diseases, No. 119, South Fourth Ring West Road, Fengtai District, Beijing 100070, China.

Received: 14 May 2019 Accepted: 18 October 2019

Published online: 29 October 2019

\section{References}

1. McDowell BD, Wallace RB, Carnahan RM, Chrischilles EA, Lynch CF, Schlechte JA. Demographic differences in incidence for pituitary adenoma. Pituitary. 2011;14:23-30.

2. Lecoq AL, Kamenicky P, Guiochon-Mantel A, Chanson P. Genetic mutations in sporadic pituitary adenomas-what to screen for? Nat Rev Endocrinol. 2015;11:43-54.

3. Amirjamshidi A, Mortazavi SA, Shirani M, Saeedinia S, Hanif H. Coexisting pituitary adenoma and suprasellar meningioma-a coincidence or causation effect: report of two cases and review of the literature. J Surg Case Rep. 2017;2017:rjx039.

4. Ruiz-Juretschke F, Iza B, Scola-Pliego E, Poletti D, Salinero E. Coincidental pituitary adenoma and planum sphenoidale meningioma mimicking a single tumor. Endocrinol Nutr. 2015;62:292-4.

5. Bondy M, Ligon BL. Epidemiology and etiology of intracranial meningiomas: a review. J Neurooncol. 1996;29:197-205.

6. Curto L, Squadrito S, Almoto B, Longo M, Granata F, Salpietro F, Torre ML, Marini F, Trimarchi F, Cannavo S. MRI finding of simultaneous coexistence of growth hormone-secreting pituitary adenoma with intracranial meningioma and carotid artery aneurysms: report of a case. Pituitary. 2007:10:299-305.

7. Herrero-Ruiz A, Villanueva-Alvarado HS, Corrales-Hernandez JJ, Higueruela-Minguez C, Feito-Perez J, Recio-Cordova JM. Coexistence of GH-producing pituitary macroadenoma and meningioma in a patient with multiple endocrine neoplasia type 1 with hyperglycemia and ketosis as first clinical sign. Case Rep Endocrinol. 2017;2017:2390797. 
8. Concolino P, Costella A, Capoluongo E. Multiple endocrine neoplasia type 1 (MEN1): an update of 208 new germline variants reported in the last nine years. Cancer Genet. 2016;209:36-41.

9. Agarwal SK. The future: genetics advances in MEN1 therapeutic approaches and management strategies. Endocr Relat Cancer. 2017;24:T119-34.

10. Weber F, Mulligan LM. Happy 20th anniversary MEN1: from positional cloning to gene function restoration. Endocr Relat Cancer. 2017;24:E7-11.

11. Asgharian B, Chen YJ, Patronas NJ, Peghini PL, Reynolds JC, Vortmeyer A, Zhuang Z, Venzon DJ, Gibril F, Jensen RT. Meningiomas may be a component tumor of multiple endocrine neoplasia type 1. Clin Cancer Res. 2004;10:869-80.

12. Wu YJ, Wong BS, Yea $\mathrm{SH}, \mathrm{Lu} \mathrm{Cl}$, Weng $\mathrm{SH}$. Sinularin induces apoptosis through mitochondria dysfunction and inactivation of the pl3K/Akt/ mTOR pathway in gastric carcinoma cells. Mar Drugs. 2016;14:E142.

13. Chen S, Fisher RC, Signs S, Molina LA, Shenoy AK, Lopez MC, Baker HV, Koomen JM, Chen Y, Gittleman H, et al. Inhibition of PI3K/Akt/mTOR signaling in PI3KR2-overexpressing colon cancer stem cells reduces tumor growth due to apoptosis. Oncotarget. 2017;8:50476-88.

14. Pachow D, WickW, Gutmann DH, Mawrin C. The mTOR signaling pathway as a treatment target for intracranial neoplasms. Neuro Oncol. 2015;17:189-99.

15. Li J, Li C, Wang J, Song G, Zhao Z, Wang H, Wang W, Li H, Li Z, Miao Y, et al. Genome-wide analysis of differentially expressed IncRNAs and mRNAs in primary gonadotrophin adenomas by RNA-seq. Oncotarget. 2017:8:4585-606.

16. Pachow D, Andrae N, Kliese N, Angenstein F, Stork O, Wilisch-Neumann A, Kirches E, Mawrin C. mTORC1 inhibitors suppress meningioma growth in mouse models. Clin Cancer Res. 2013;19:1180-9.

17. Surace El, Lusis E, Haipek CA, Gutmann DH. Functional significance of S6K overexpression in meningioma progression. Ann Neurol. 2004:56:295-8.

18. James MF, Han S, Polizzano C, Plotkin SR, Manning BD, Stemmer-Rachamimov AO, Gusella JF, Ramesh V. NF2/merlin is a novel negative regulator of mTOR complex 1, and activation of mTORC1 is associated with meningioma and schwannoma growth. Mol Cell Biol. 2009;29:4250-61.

19. Khandwala HM, McCutcheon IE, Flyvbjerg A, Friend KE. The effects of insulin-like growth factors on tumorigenesis and neoplastic growth. Endocr Rev. 2000;21:215-44.

20. O'Neil TK, Duffy LR, Frey JW, Hornberger TA. The role of phosphoinositide 3-kinase and phosphatidic acid in the regulation of mammalian target of rapamycin following eccentric contractions. J Physiol. 2009;587:3691-701.

21. Liang J, Slingerland JM. Multiple roles of the PI3K/PKB (Akt) pathway in cell cycle progression. Cell Cycle. 2003;2:339-45.
22. Mafficini A, Scarpa A. Genomic landscape of pancreatic neuroendocrine tumours: the International Cancer Genome Consortium. J Endocrinol. 2018:236:R161-7.

23. Majumder PK, Febbo PG, Bikoff R, Berger R, Xue Q, McMahon LM, Manola J, Brugarolas J, McDonnell TJ, Golub TR, et al. mTOR inhibition reverses Akt-dependent prostate intraepithelial neoplasia through regulation of apoptotic and HIF-1-dependent pathways. Nat Med. 2004;10:594-601.

24. Wen PY, Chang SM, Lamborn KR, Kuhn JG, Norden AD, Cloughesy TF, Robins HI, Lieberman FS, Gilbert MR, Mehta MP, et al. Phase I/II study of erlotinib and temsirolimus for patients with recurrent malignant gliomas: North American Brain Tumor Consortium trial 04-02. Neuro Oncol. 2014;16:567-78.

25. Lee EQ, Kuhn J, Lamborn KR, Abrey L, DeAngelis LM, Lieberman F, Robins $\mathrm{HI}$, Chang SM, Yung WK, Drappatz J, et al. Phase I/II study of sorafenib in combination with temsirolimus for recurrent glioblastoma or gliosarcoma: North American Brain Tumor Consortium study 05-02. Neuro Oncol. 2012;14:1511-8.

26. Lassen U, Sorensen M, Gaziel TB, Hasselbalch B, Poulsen HS. Phase II study of bevacizumab and temsirolimus combination therapy for recurrent glioblastoma multiforme. Anticancer Res. 2013;33:1657-60.

27. Franz DN, Belousova E, Sparagana S, Bebin EM, Frost M, Kuperman R, Witt O, Kohrman MH, Flamini JR, Wu JY, et al. Efficacy and safety of everolimus for subependymal giant cell astrocytomas associated with tuberous sclerosis complex (EXIST-1): a multicentre, randomised, placebo-controlled phase 3 trial. Lancet. 2013;381:125-32.

28. Krueger DA, Care MM, Holland K, Agricola K, Tudor C, Mangeshkar P. Wilson KA, Byars A, Sahmoud T, Franz DN. Everolimus for subependymal giant-cell astrocytomas in tuberous sclerosis. N Engl J Med. 2010;363:1801-11.

29. Franz DN, Leonard J, Tudor C, Chuck G, Care M, Sethuraman G, Dinopoulos A, Thomas G, Crone KR. Rapamycin causes regression of astrocytomas in tuberous sclerosis complex. Ann Neurol. 2006;59:490-8.

30. Cerovac V, Monteserin-Garcia J, Rubinfeld H, Buchfelder M, Losa M, Florio T, Paez-Pereda M, Stalla GK, Theodoropoulou M. The somatostatin analogue octreotide confers sensitivity to rapamycin treatment on pituitary tumor cells. Cancer Res. 2010:70:666-74.

\section{Publisher's Note}

Springer Nature remains neutral with regard to jurisdictional claims in published maps and institutional affiliations.
Ready to submit your research? Choose BMC and benefit from:

- fast, convenient online submission

- thorough peer review by experienced researchers in your field

- rapid publication on acceptance

- support for research data, including large and complex data types

- gold Open Access which fosters wider collaboration and increased citations

- maximum visibility for your research: over 100M website views per year

At BMC, research is always in progress.

Learn more biomedcentral.com/submissions 